\title{
1 \\ Ringworm: A Disease of Schools and Mass Schooling
}

Education is a near universally recognised 'good' across histories of the modern world, with more and better quality schooling seen as a progressive social reform and a marker of a modern, civilised society. However, the introduction of mass schooling in Britain and America was the product of a social and political struggle which was not easily won. ${ }^{1}$ Few disagreed that education improved the minds of pupils, but many people argued that it was not always good for their bodies; indeed, schools became great centres of contagion. Epidemics of major childhood infections such as measles, diphtheria and chickenpox periodically affected institutions and in some cases led to school closures. ${ }^{2}$ Less recognised then, as now, was that schools were sites of exchange of endemic, social diseases, from serious, typically fatal infections, such as tuberculosis, through to endemic conditions, such as ringworm, which had mild symptoms but carried severe social stigma. The term 'ringworm' is very old and comes from the circular patches of peeled, inflamed skin that characterises the infection. In medicine at least, no one understood it to be associated with worms of any description.

In the early part of the nineteenth century, ringworm was well recognised by doctors and the public as an inflammation of the scalp, associated with reddening of the skin, itching, circles of peeling skin and hair loss. In children it was also popularly known as 'scald-head', a term derived from 'scaled' and 'scabby' rather than burns, and in medicine as a form of porrigo - skin complaints associated with the production of pustules. The naming and classification of skin diseases had been hugely contested from the 1790s until the publication of a system proposed by the English physician Robert Willans, who worked at the Carey Street Public Dispensary in London. ${ }^{3}$ However, by the 1830s, when serious medical attention first focused on ringworm, the debate had settled to 
become one between those who saw the condition as localised in the skin and those who also looked to constitutional, internal factors. Both sides agreed that it was contagious and prevalent in children, especially the poor, who lived in crowded conditions and in orphanages, boarding schools and other institutions. The exciting cause was mostly talked about as a 'fungus', but susceptibility was explained in terms of the child having immature skin, a weak general constitution, dirty skin and poor hygiene, or all of these.

The role of 'seed and soil' in the causes, pathology, treatment and prevention of ringworm was debated throughout the nineteenth century and beyond. In this chapter, we tell the story of how and why the understanding of doctors and the public about the nature of ringworm changed in the period 1830-1910, focusing on the disease in school children. We first set the story of ringworm in the context of the emergence of dermatology, a specialism that grew largely in outpatient and dispensary settings. At this time, fungal diseases generally were understood mostly to affect the skin and outer membranes of the body, which was the domain of surgeons and later the new specialists in dermatology. We discuss the role of dermatologists in the development and spread of germ theories of skin diseases, showing that they were pioneers amongst clinicians in working with these ideas and changing to antiseptic practices. Our narrative then turns to the problem of ringworm in school children and attempts to manage the disease for sufferers and their families, and we show that the social consequences and stigma of the infection were far worse than the disease itself. Finally, we analyse new treatments, especially the use of X-rays, and school medical inspections, where children worried about the nurse finding both nits and ringworm.

\section{'Scald-head'}

Robert Willans, London's leading skin specialist in the late eighteenth and early nineteenth centuries, reported that in his career he had seen children from over 200 schools and colleges in London affected by ringworm. While its effects on the physical body were localised and relatively mild, on personal development they were serious, as Samuel Plumbe, Willan's successor, explained in $1835 .{ }^{4}$

In the earlier periods of the lives of children there is no disease, no species of deviation from sound health, if we except scrofula, which operates so perniciously on the future prospects of the individual, as ring-worm, if of long continuance. The moment an unfortunate child 
is found by the schoolmaster or the schoolmistress with a spot on the head, the latter, very properly (not merely for interest's sake, but as a duty to the parents of all the other children), sends the child home, refuses to readmit until thoroughly cured. The consequence of this is, to the unfortunate child, a loss of time at that period of life when it can be least afforded, the period of early education. ${ }^{5}$

It was not only children who suffered, their teachers did too. Plumbe observed that the disease was 'destructive of the best instructors of children, for the conductors of establishments of previously high character and reputation found their pupils drop off in large numbers, and many good schools have been utterly ruined by it' ${ }^{6}$

There are no figures for the incidence of ringworm in the nineteenth century, but every indication is that it was very prevalent. ${ }^{7}$ There were, for instance, a huge number of proprietary ointments, lotions and potions sold by local chemists and self-treatment advice was proffered in popular health manuals and advertisements. The 1790 edition of William Buchan's Domestic Medicine recommended 'keeping the head very clean, cutting off the hair, combing and brushing away the scabs, \& c.', plus the use of ointments. ${ }^{8}$ Mrs Beeton offered several treatment regimes in her Book of Household Management, including the application of sulphur and treacle, creosote, or calomel. ${ }^{9}$ There were numerous reports of cases and treatments in national and regional medical journals, for all types of infection. ${ }^{10}$ At many sites on the body, the characteristic rings were hidden by clothing and hard to see, which meant that sufferers and doctors found it difficult to distinguish ringworm from other inflammatory afflictions, such as favus, eczema, psoriasis and impetigo. Surgeons considered therapy relatively straightforward on any part of the body except the scalp, where ringworm was typically persistent. Although the disease affected all ages, medical discussion focused on children and on their scalps. ${ }^{11}$ It was the most visible form of the disease, both medically and socially, as infected children were stigmatised as unclean and their parents regarded as uncaring.

In Britain, ringworm first attracted national medical and public attention in 1835, following reports of its high prevalence at Christ's Hospital School, one of London's foremost public schools, which included amongst its old boys Charles Lamb and Samuel Taylor Coleridge. ${ }^{12}$ In this outbreak there were two issues: firstly, the infection was often said to be an indicator of poor management by the governors and staff, as well as damaging to the reputation of the school; and secondly, if children were excluded for weeks on end, their education was suffering and 
the school was losing income. ${ }^{13}$ An editorial in the Lancet complained that the governors had been negligent in not drawing upon the expertise of doctors, especially those who had dealt successfully with other serious outbreaks at the London Orphan Asylum and the Royal Naval School. ${ }^{14}$ A committee of Christ's governors was appointed to look into the problem and they invited Plumbe to advise them. His report nicely illustrates medical thinking on the affliction at the time in terms of exciting causes (contagion) and predisposing causes (general health and cleanliness). As was typical of the fractious character of skin specialists at this time, he was dismissive of Robert Willans - who he saw as no better than a nostrum monger - and of the French dermatologists. His view of the nature of ringworm was that it was both constitutional and contagious:

The simple circular contagious ringworm is not, as has been supposed by many, produced only by infection or contagion. It arises in a very large portion of cases from the same sources as other diseases of the skin, such as improper diet, producing constipation of the bowels; restraint of the due and healthy exercise of children; repletion from over feeding, or from merely a single indulgence of sweet-meats or cakes, producing acidity. Yet thus originating it is quite as contagious as that which has spread directly in a family, from child to child, by contact, where no derangement of the stomach or system can be traced or suspected. ${ }^{15}$

Plumbe advised surveillance to control the spread of the disease by examining boys on entry, washing bedding regularly and isolating those infected. This might involve moving those suffering to separate rooms, or simply making them wear protective caps or headwear. He also wanted pupils to have improved diets, both in quantity and in quality. He linked this to the danger of scurvy, writing that the almost entire privation of vegetables tends to produce, if it be not the sole cause of the eruptive diseases'. ${ }^{16}$ Plumbe was a 'skin doctor' before the era of specialisation, so it would be anachronistic to characterise him as a dermatologist; indeed, that term did not gain currency until the 1880s, but he does represent the common situation in the nineteenth century where surgeons had known areas of specialist expertise. ${ }^{17}$

\section{Dermatology and fungus theories of skin diseases}

Historians of nineteenth century British clinical medicine have highlighted that key national characteristic of resistance to specialism in 
hospital practice amongst elite physicians and surgeons and the celebration of the virtues of the generalist. ${ }^{18}$ "The narrow specialism of dermatology', as it was termed in 1874, was one of a number of organor technique-based specialist areas that drew the wrath of critics. ${ }^{19}$ For example, a reviewer of Mapother's Diseases of the Skin, published in 1875, was severe on the author's expertise and his claims to special competence.

It is, indeed, but too true that the great body of specialists is composed largely of those who are intellectually quite incapable of comprehending all the departments for the healing arts. They succeed only by limiting their sphere of action; they triumphantly paddle in pools who would not live a moment in the stream. With the exception of ophthalmologists, specialists cannot, as a rule, be said to be amongst the best educated of the profession; and worse than all, the exclusive practice of some small speciality tends to perpetuate and increase ignorance, if it do not also deprave professional morals. ${ }^{20}$

However, Edward Dillon Mapother was no exclusive practitioner. ${ }^{21} \mathrm{He}$ had been Medical Officer of Health for Dublin in the 1860s, wrote extensively on medical education, and was appointed Professor of Anatomy and Physiology at the Royal College of Surgeons of Ireland, eventually becoming its president. He had special interests in syphilis and gout, as well as in skin diseases.

Why was so much scorn poured on specialists? One explanation was the rivalry between surgeons and physicians, though this was complicated by the emergence of another divide between general practitioners and consultants. ${ }^{22}$ Both consultant surgeons and physicians attacked specialisation, but many practitioners had niches with particular diseases, and combined general and specialist work. The case of the emergent specialism of dermatology is instructive. ${ }^{23}$ It grew from surgical practice after the mid-nineteenth century, with specialist journals being published from the 1870s. The diagnosis and treatment of skin diseases had been a large and important part of surgeons' work and hence income. The future of general surgery seemed to lie in two directions: on the one hand extending the number and range of operations, while on the other hand becoming more 'medical'. For example, in the treatment of syphilis, the cauterisation or excision of primary lesions on the skin was regarded as ineffectual and surgeons relied more upon constitutional treatment with mercury. ${ }^{24}$ Treating syphilis may have been a 
good source of income for surgeons, but sufferers were stigmatised and this rubbed off on surgeons. In fact, the term 'quack', widely applied to so-called specialists, was a contraction of 'quacksalver', or quicksilver, one of the most widely used specific treatments for syphilis.

Specialist practice in skin diseases was largely in hospital outpatient departments and dispensaries, the first of which, the Royal London and Westminster Infirmary for the Treatment of Cutaneous Diseases, was opened in $1819 .{ }^{25}$ In the capital, a Hospital for Diseases of the Skin (later the Blackfriars Skin Hospital) followed in 1841, with satellite dispensaries opening in 1843, 1844, 1850, 1851 and $1857 .{ }^{26}$ A new era in skin hospitals began in 1863 with the opening of the St John's Hospital for Disease of the Skin, followed by many more such institutions. ${ }^{27}$ John Laws Milton founded St John's initially with the support of leading figures on diseases of the skin, such as Erasmus Wilson, William Tilbury Fox and J. Mill Frodsham. ${ }^{28}$ The new skin hospitals had few beds and their dispensary work directly challenged the businesses of local general practitioners and elite consultants. In response, many voluntary hospitals set up 'skin departments', promising the best of all worlds: specialist, accessible care without hospitalisation, available in general hospitals where other specialist and general consultants were available.

Erasmus Wilson was Britain's leading authority on diseases of the skin and he founded the short-lived Journal of Cutaneous Medicine in $1867 .{ }^{29}$ He was a polymath and populariser, who published books on the skin, food and Egyptology, and is best known for funding the transportation of Cleopatra's Needle to London in 1878. Wilson popularised the term 'dermatology', first lecturing on the subject in 1840, and publishing On Diseases of the Skin: Practical and Theoretical Treatise in 1842. His private practice and investments were so successful that in 1869 he donated monies to the Royal College of Surgeons to establish a professorship of dermatology, which he held from 1869 to 1878, giving an annual series of lectures. In his own clinical practice, Wilson saw no conflict between generalism and specialism, but he was opposed to the exclusive specialist practice of others. Although trained as a surgeon, he claimed that almost all skin diseases were internal and constitutional in origin, which required medical as much as external surgical or topical treatments. Thus, skin diseases needed to be diagnosed and treated by someone who understood the workings of the whole body, not just its outer layer. He was an opponent of contagious germ or fungal explanations of skin conditions, believing that any such matter present was a 'secondary or adventitious product' rather an exciting cause. ${ }^{30}$ 
In the 1860s, two teaching hospitals, University College Hospital and the Glasgow Western Infirmary, established dermatology departments, and appointed two men who made ringworm a model for germ theories of skin disease: Thomas M'Call (sometimes McCall) Anderson and Tilbury Fox. ${ }^{31} \mathrm{M}^{\prime}$ Call Anderson published On the Parasitic Affections of the Skin in 1861 and Tilbury Fox published his Skin Diseases of Parasitic Origin two years later. ${ }^{32}$ Like Wilson, Tilbury Fox opposed specialisms, whereas $\mathrm{M}^{\prime}$ Call Anderson argued that this was how progress was being made in medicine in France and Germany and that Britain should follow. ${ }^{33}$ Yet $\mathrm{M}^{\prime}$ Call Anderson was another example of someone who combined general and specialist practice. He became Professor of Clinical Medicine at the Glasgow Western Infirmary and then Regius Professor in 1904, and his obituary celebrated how he maintained specialist work and writing on skin diseases, along with clinical teaching and running a large private practice. Tilbury Fox and M'Call Anderson united against Wilson's claim that fungi had no causal role in skin diseases. Given his dominant position, it is unsurprising that Wilson represented what was termed the 'British school of dermatology' that saw most skin diseases to be of internal, constitutional origin - mostly forms of eczema - which required internal remedies.

\section{Fungus germs}

From the 1850s, ringworm was regarded as a fungus disease. This made it an early candidate to be a germ disease when debates about the causes of infectious and contagious diseases turned to microorganisms in the 1870 s. $^{34}$ Some histories of germ theories of disease, anticipating the closure on bacterial causes in the 1880s, have ignored the many types of entity - animal, vegetable and mineral - that were candidates to be disease germs in 1860s and 1870s. Good examples of such openness were the views of Samuel Wilks, the leading London physician. In his Address in Medicine at the British Medical Association (BMA) in June 1872, he spoke variously of disease being caused by 'vegetable germs', 'a fungus', 'specific organic particles' and 'a virus' ${ }^{35}$ Wilks also made the point that the 'seeds' of disease, its germs, needed to find suitable 'soil'. Ringworm was one of his examples and he placed it, no doubt surprisingly for modern readers, alongside cancer as a disease that grew and spread within the body.

A ringworm grows and grows wherever the soil is propitious; the itch insect spreads over the body and the hydatid often swells until its 
host is destroyed. Cancer-cells divide and propagate until they have killed their victim which has supplied them with nourishment; and the germs of small-pox will do the same. ${ }^{36}$

Another key issue with fungi (the collective botanical name at the time was the Mycetes) was whether they were made up of fixed species, or were they so simple that their biology was shaped by the conditions in which they grew. Moreover, if there were fixed species, how could these be differentiated when their forms and modes of reproduction were so variable.

The same question was important in germ theories of diseases, not least with bacterial versions. The scientific name for bacteria at this time was the Schizomycetes, literally, 'fission fungi'. ${ }^{37}$ Being surgeons by training, dermatologists were early adopters of antiseptics, if not converts to germ theories of putrefaction and inflammation, and through the promotional activities of Joseph Lister had early and consistent exposure to new ideas on germs. The standard chemical antiseptic, carbolic acid, was tried as a fungicide with ringworm and other skin infections, along with sulphurous acid, acetic acid, iodine and mercuric chloride. ${ }^{38}$ However, the lengthy applications of such caustic substances meant that the treatment was often worse than the cure.

The books of Tilbury Fox and M'Call Anderson, which many read as suggesting that almost all skin diseases were of fungal origin, prompted debates that anticipated many of the issues that divided opinion over bacterial germ theories of disease in the last quarter of the nineteenth century. ${ }^{39}$ First, there was the question of whether any fungi found in diseased skin were necessary causes of disease or just concomitants. ${ }^{40}$ Second, doctors asked whether fungi, when present, could only develop on dead tissue, acting as saprophytes; or whether they could actually invade and colonise living tissue, as infective agents or contagium viva. It was in this vein that the cholera fungus controversy in the late 1840s and 1850 s had been framed. ${ }^{41}$ Third, if fungi were agents of disease, was there one pathogenic fungus that produced different diseases because its effects and form depended on the tissue on which it grew: that is, it was pleomorphic (pleo - many + morphic - form). Or, did distinct species of pathogenic fungi produce different diseases? In his volume, Tilbury Fox argued that all pathogenic fungi were forms of Tinea - the ringworm fungus - which he made 'the generic term for parasitic affections of the surface', echoing the views of the Ernst Hallier in Germany on the pleomorphic character of fungi. ${ }^{42}$ Against this, $\mathrm{M}^{\prime}$ Call Anderson maintained that different fungi caused distinct and specific diseases, and that they 
could do so in both dead and living tissue. He classed fungal infections as 'vegetable parasitic affections', placing them alongside animal parasitic ones, such as scabies, and those caused by 'poisons' or 'viruses', such as syphilis.

The impact of bacteriology on the management of skin diseases was to shift treatments to be anti-germ. ${ }^{43}$ As noted above, doctors recommended germ-killing antiseptics, but also tried to break the passage of germs by 'isolating' the infected area, by covering it with a dressing or grease of some type. The ringworm caps worn by children combined all of these. The exclusion of infected children from school became more common and there were some suggestions of isolating families in their homes. At the same time, most doctors continued to recommend measures that aimed to strengthen the bodily 'soil' against the 'seeds' of disease. Although it would be wrong to make too much of the conjunction, the Dermatological Society of London was founded in 1882, the very same year in which Koch announced his discovery of the Tubercle bacillus, which could also infect the skin and was associated with leprosy and lupus. ${ }^{44}$ From this time, leading dermatologists associated particular germs with specific skin diseases. ${ }^{45}$

\section{Ringworm in schools - ringworm schools}

Outbreaks of ringworm in schools, workhouse and other institutions were reported throughout the mid-Victorian period, but they attracted little medical or public attention. However, things changed after the introduction of mass schooling following the 1870 Education Act and Tilbury Fox was called upon in 1875 for advice on control and prevention by the government. ${ }^{46}$ School attendance had revealed both the 'verminous condition' of many children and created 'nurseries of ringworm' as classroom and playgrounds were ideal for spreading infection. ${ }^{47}$ Ringworm was one of a number of health problems that were taken up by medical officers of health, and later school medical officers. ${ }^{48}$ The Lancet established a Commission on the Sanitary Condition of Our Public Schools, which released a report in 1875, calling for improvements in buildings, dietary and welfare, plus measures to control infectious diseases, especially scabies, scarlet fever and ringworm. ${ }^{49}$ There was broad medical agreement that children with ringworm should be excluded from school, though there was disagreement on remedial action: some doctors recommended shaving the head and wearing a cap, others preferred the vigorous application of disinfectant ointments and lotions. When children who had been excluded could return was, in 
fact, more of an issue than when to exclude them. ${ }^{50}$ Capped and shaved ringworm children represented popular fears of contagion, though doctors often played down the link with dirt and insanitary environments, claiming ringworm was simply a 'catching', germ disease. Indeed, Robert Liveing, a leading authority on dermatology, noted in 1879 that 'gutter children' tended to be exempt from infection, despite being filthy and unkempt. Why? Because they did not attend school, nor did they ever brush their hair, so they were never exposed to the germs. ${ }^{51}$

The leading medical authority on ringworm in the latter part of the nineteenth century was Herbert Alder Smith, who spent his whole career as a medical officer at Christ's Hospital School at Newgate in London. ${ }^{52}$ His book, Ringworm: its diagnosis and treatment, went through four editions between 1880 and $1897 .{ }^{53}$ Alder Smith took the view that ringworm was a local infection that had no impact on general health; hence, it should be treated locally, with general remedies only used as an adjunct. He only saw the bodily 'soil' in terms of age and diet, making the familiar point that the disease was rarely present after puberty and that children who disliked fat, along with those who were ill-nourished, seemed more vulnerable. He gained a readership in part because of his experience and in part because he offered a novel treatment. He claimed that he had identified 'nature's method of effecting a cure', a type of inflammation he termed 'kerion' which led to hair loss. ${ }^{54}$ To produce a localised 'kerion' reaction artificially, he applied drops of croton oil, a widely used counter-irritant, to individual hair follicles to make them 'tender, swollen, red and infiltrated'; the aim was to produce 'a speedy and certain cure' by depilation. ${ }^{55}$

However, this was one was amongst hundreds, possibly thousands, of formulae that doctors prescribed for ringworm, with new treatments being regularly reported in medical journals. ${ }^{56}$ On hairless parts of the body, such as the hands and face, ringworm was readily treatable, with school children finding ordinary writing ink very effective, probably because it contained, 'gallic acid and tannin (derived from vegetable galls), ferrous sulphate, mucilage, and haematoxylin (derived from logwood)'. However, ringworm on the scalp was often unmoveable, hence the attraction of shaving and chemical depilation. In addition to medical remedies, ringworm was included in the conditions cured by the huge number of proprietary or popular remedies sold by chemists and available from many sources. For example, advertised in the Manchester press in 1889 was the 'Health Restorer Ointment', which was said to be the 'Best, Safest and Speediest Cure in the World for Burns, Scalds, Ulcer, Chilblains, Itch, Ringworm, Scabbed Heads, Eczema, and all Skin 
Diseases', whilst 'Old Doctor Townsend's blood purifying 'Old American Sarsaparilla' offered cleansing from within. ${ }^{57}$ Londoners could try 'Cook's Antiseptic Soap', which had been endorsed in the Lancet in May 1888, and 'Grasshopper Ointment', which also cured 'Bad Legs, HouseMaids Knee, Ulcerated Joints, Carbuncles, Poisoned Hands, Tumours, Cancers and Abscesses'..$^{58}$

The main impact of germ ideas and practices was in public health, with a switch to policies that focused on individuals as carriers of pathogens and practices of disinfection, isolation and notification. ${ }^{59}$ With regard to infectious diseases overall, this change particularly affected children, who were by far the majority of patients in the new isolation hospitals and whose health was targeted by school medical inspections. ${ }^{60}$ A prominent example of the new concerns and approaches was in 1891, when the Poor Law North Surrey Board School in Anerley called in a top London dermatologist to advise on dealing with the large number of children with persistent ringworm. ${ }^{61}$ Joseph Payne found 23 out of 45 children had been in isolation for over a year and five had suffered for over four years. He found no fault in the 'thorough, scientific and conscientious' response of the teachers, the medical officer or the managers. ${ }^{62}$ He made recommendations, but the problem persisted. Two years later, in May 1893, the school turned to another London specialist, Dr Alfred Eddowes. He found 47 cases and, while agreeing that the medical officer was highly competent, he nevertheless recommended that he took overall control, as with ringworm 'detail' was all important. ${ }^{63} \mathrm{He}$ visited once a fortnight over four months, after which he claimed to have cured 25 children and improved the remainder; eventual eradication seemed inevitable. ${ }^{64}$

Policies for ringworm were developed along similar lines to diphtheria and scarlet fever, although it was much less serious, because of its impact on sufferers and their families. It became, quite literally, a social disease. Infected children were given special status and treatment because they seemed manifestly 'unclean' and stigmatised by other children and their families, and by neighbours. In addition, teachers and doctors expressed concerns about the consequences of exclusion for the individual, their family and the future mental fitness of the nation. Abraham and Eddowes explained the issues in 1894.

Now that school attendance is compulsory and that the well-caredfor children of poor but respectable families often have to associate at school with those of the dirtiest and most careless classes of the community it is a moral duty that all reasonable precautions should be 
insisted on by the authorities in order to minimise the risk of infection from the diseased to the healthy. A skin disease also, contracted at school, may be taken home to the brothers and sisters. ${ }^{65}$

Malcolm Morris, a leading dermatologist and syphilologist, while unwavering on the need for the strict exclusion of affected children, called for a survey to determine the extent of the problem, suggesting that there should be special ringworm schools where excluded children could continue their education. ${ }^{66}$

Ringworm was targeted by London's Metropolitan Asylums Board (MAB) when, in 1897, it included specific measures in its plans for a variety of special institutions 'to eradicate the physical taints of pauperism and to place them on a fairer level of health for the race of life' ${ }^{67}$ Ringworm was included alongside contagious diseases of the eye, convalescence and open air treatment, mental defectives, the physically disabled, and 'young offenders' ${ }^{68}$ The first, and as it turned out, temporary special institution for ringworm was the Bridge School in Witham, Essex, started in 1901. It was replaced by the Downs Ringworm School (also known as Banstead Road School) in Sutton, Surrey, in February 1903. Here children were housed in blocks of 70 beds, attended lessons within the institution, and were treated by the daily bathing of their scalp, intensive applications of lotions and the extraction of diseased hairs. ${ }^{69}$ In the first ten months, 618 children were admitted, of whom 208 were discharged, 153 'cured' and the remainder recalled by local Poor Law Guardians. ${ }^{70}$

Children sent to special schools were the exception; most children with ringworm were excluded from school and treated at home. Some doctors thought exclusion unnecessary and unproductive, as very few parents were able to keep infected children away from their siblings, or from playing with other children after school. Phineas Abraham, surgeon at the Hospital of the Skin at Blackfriars, London, argued in 1900 that when a child's head was 'kept greasy with germicidal ointments and always covered with a closely fitted cap', they should be allowed to attend school. ${ }^{71}$ Everyone who wrote on the subject agreed that the ringworm caused more social than physical suffering. Infected children had no pain (other than from itching and the caustic lotions), no general illness, and there were no permanent effects on the skin or hair. Their suffering was 'exclusion from school and, to a great extent, banishment from society'.$^{72}$ Parents endured some degree of stigma and had to manage their child's isolation. ${ }^{73}$ Also, while doctors accepted that all 
social classes were vulnerable and that 'dirt' as such was not a factor, ringworm was far less common amongst the well-to-do, because they were allegedly 'less ignorant and gave greater care to their offspring'.

Doctors' confidence in their ability to prevent and treat the condition grew as they increasingly believed that they knew their enemy. ${ }^{74}$ The French dermatologist, Raimond Sabouraud, who had trained at the Institut Pasteur, was a leading doctor at the famous Hôpital Saint-Louis in Paris, and published major works on the biology of ringworm organisms. In 1886, the Saint-Louis had opened its 'L'ecole des teigneux', or 'ringworm school', colloquially known as a school for the scabby children. A decade later it opened 'le laboratoire municipal des teignes de la Ville de Paris'. ${ }^{75}$ Sabouraud was the first director and his institution became famous for adapting bacteriological methods to working with fungi in the laboratory and for work on les teignes - 'ringworm' ${ }^{76} \mathrm{He}$ identified three groups of causal organisms, promising closure to the uncertainty over whether there was one ringworm fungus or many, and the degree to which species were pleomorphic. ${ }^{77}$ His publications were well received, but it was above all his demonstrations and displays at the 1896 International Congress of Dermatology in London that were decisive in enrolling others to his standpoints. ${ }^{78}$ In 1897 Herbert Aldersmith (he changed his name from Alder Smith in the 1890s) wrote that Sabouraud's 'new views have completely revolutionised all older ones, and necessitated the separate description of the different forms of ringworm, and their microscopic appearances'. ${ }^{79}$

A key finding was distinguishing between ectothrix infections that affected the outside of the hair (e.g. Microsporon spp.) and endothrix ones that invaded the hair shaft (e.g. Trichophyton spp.) There was some dissent in Britain, notably from two leading London dermatologists, Thomas Colcott Fox and Frank Blaxall, of the Westminster Hospital, who maintained that Trichophyton and Microsporon were not in separate families, and from Leslie Roberts who emphasised physiological over morphological differences. ${ }^{80}$ Nonetheless, Sabouraud's classification framed medical work on ringworm for the next decade, not least in epidemiological surveys of the incidence of the different organisms. ${ }^{81}$ For example, a survey in 1903 found that over 90\% of ringworm cases in London hospitals were due to Microsporon audouinii and Microsporon canis, the latter found in dogs, which compared with 60\% in Metropoli$\tan$ Asylums Board school children. ${ }^{82}$ In Paris the main species were M. audouinii and T. mentagrophytes, the latter having a reservoir in dogs, cats and other animals. 
Medical interest in ringworm in the United States was much less pronounced than in Britain. ${ }^{83}$ The schooling system was more fragmented, being organised at state and local level across a vast area. While education was regarded as very important and widely available, compulsory schooling in all states arrived around 1900, three decades after Britain. ${ }^{84}$ There was no dedicated American medical publication on ringworm until 1921, when John P. Turner's booklet Ringworm and its successful treatment was published. ${ }^{85}$ Turner was a medical inspector of public schools in Philadelphia, though he wrote as a general practitioner recommending the application of simple chemicals and cleanliness. There were few articles in American medical journals on ringworm, though cases were discussed at dermatological meetings, along with scabies, pediculosis and impetigo, but as problems of individual hygiene rather than being associated with age or class. The main problem was with M. canis, perhaps reflecting the closeness of humans to pets and other animals, even in urban settings in America at this time.

However, medical and public responses to the related fungal disease of favus were quite different. By the turn of the century, favus had been linked to the fungus Achorion schoenleinii and had been found to be the most common skin infection amongst immigrants from Europe. Favus was characterised as a 'loathsome disease' and, after trachoma, a contagious eye infection, was the second largest cause of immigrants being rejected, or sent to isolation for treatment after inspections at Ellis Island. ${ }^{86}$ Howard Markel has discussed why trachoma attracted so much attention given its low incidence and the same argument applies to favus; namely, that it was an easily recognised condition that was made a marker of the person being 'unclean' and hence 'unfit' for acceptance into the United States. ${ }^{87}$ In American cities, school children with ringworm were sometimes excluded, but there were no special institutions as there were in Paris and London. ${ }^{88}$

\section{'The X-ray Revolution'}

In the 1900s, Raimond Sabouraud's reputation as the world's leading authority on ringworm was taken to a new level when he pioneered the X-ray treatment of infected scalps. ${ }^{89}$ At this time, X-rays were one of the technological wonders of the age as 'skiagraphs' revealed the body's internal structure. They promised not just the transformation of medicine but also wider social and cultural progress. ${ }^{90}$ Sabouraud's innovation, first reported in 1904, used X-rays not to kill fungi, but to produce depilation. The rationale was to remove the 
nidus of infection and allow germicides or fungicides easier penetration into hair follicles. As noted already, depilation was an accepted as an effective means of treating ringworm; indeed, Aldersmith had written in 1897 that,

In fact, my chief experiments during the last few years have been an effort to discover something that will always cause disease hairs to fall out from patches of ringworm, for I fully believe that this troublesome disease will in time be cured by this method and not by the discovery of new parasiticides. ${ }^{91}$

However, attempts to achieve this by chemical and mechanical means had proved fraught with difficulties, not least because the inflammation and skin damage meant that the treatment was irritating and opened the skin to other infections.

The potential of X-rays for the treatment of skin diseases had been explored from the very beginning of their introduction into medicine in the mid-1890s. The ability to 'see' inside the body excited contemporaries and has interested historians, but in many hospitals their main use, along with the Finsen lamp, was for the topical treatment of skin diseases. ${ }^{92}$ Around 1900, the potency of X-rays was doubleedged: they could reveal the inner structure of the body and cure certain diseases, but they could also maim and kill if too high a dose was given. The most immediate and visible damage caused by X-rays was to the skin. Indeed, it was this experience that led doctors to explore their use as counter-irritants, germicides and fungicides. However, experimental studies quickly showed that X-rays did not readily destroy bacteria or fungi. Hair loss was noticed after incidental exposures and X-rays were said to have cosmetic as well as medical possibilities. Indeed, a report in the Lancet even suggested that exposure to $\mathrm{X}$-rays might be a more convenient method of removing a beard than conventional shaving! ${ }^{13}$ The systematic application of X-rays for depilation was first reported in 1897 by Leopold Freund, who worked at the Medizinische Universität Wien. ${ }^{94}$ He used X-rays for cosmetic procedures, removing surplus hair and unsightly features, such as hairy moles. The problem with such work was controlling the dose received by the patient. If the dose was too large, it could lead to permanent hair loss and skin damage. There is no evidence of similar experimentation amongst British and American dermatologists; however, they did keep up with the new applications developed by doctors in continental Europe. 
Freund and Schiff in Vienna were probably the first to try X-rays to treat ringworm cases, but the treatment was, and still is, identified with Sabouraud..$^{95}$ He had recognised the therapeutic value of depilation and had tried thallium acetate, otherwise used as a rat poison, but this produced severe side-effects. X-ray depilation, therefore, promised to be safer. Sabouraud's key innovations, which he developed in collaboration with Henri Noiré and Maurice Pignot, were methods and materials to control the dosage of X-rays received by patients, which were lower than with skiagraphs.${ }^{96}$ His first invention was a generator with controllable output that allowed variation in the intensity of X-rays emitted; the second was developing a chemical that changed colour on exposure to X-rays in a graded way that enabled monitoring of the dose a patient received..$^{97}$ The latter was crucial to avoid X-ray burns.

The X-ray therapy developed by Sabouraud was cumbersome. It required the patient to remain very still for up to 40 minutes, which was difficult to achieve with children, and much more so if many sessions (the contemporary term was 'séances') were required. Sabouraud claimed that five sessions on different parts of the scalp were safe; most doctors concurred, though one British doctor wrote that this was 'criminal' ${ }^{98}$ With large areas of infection there were two problems: first, the convex form of the skull meant that it was difficult to ensure even exposure; and second, it was imperative to avoid overlapping exposures that would produce burns or permanent baldness. The clinical picture reported by Sabouraud was that X-rays produced reddening of the skin and hair loss in 12-14 days. ${ }^{99}$ He wrote that once the fungi had been carried away with the hair, the doctor's task was to ensure that the treated areas did not become re-infected, which meant instructing patients on the conscientious and thorough application of fungicidal lotions. Hair started to re-grow after six to eight weeks, but did so only slowly, allowing for the long-term application of fungicidals (Figures 1.1 and 1.2).

Despite the laborious procedure, X-rays had two advantages when judged against fungicides alone and other treatments: they brought treatment times down from years to months and produced permanent cures. ${ }^{100}$ Sabouraud reported a $100 \%$ increase in his cure rates, including many that had previously been intractable; and all this reduced costs eightfold, from 2,000 to 260 francs per patient.

In Britain, X-ray treatment was taken up in the outpatient departments of voluntary hospitals and in some of the new radiotherapy clinics. The first, very positive results were published in $1905 .{ }^{101}$ The leading dermatologist, Malcolm Morris, confidently claimed that X-rays would mark, 
the beginning of a new era in the treatment of an affection which has previously been one of the stumbling blocks of medical practice. It was fitting that we should owe the means of easy victory over a peculiarly rebellious disease to the distinguished man [Sabouraud] who has done so much to dissipate the darkness in which till lately its origin was enshrouded. ${ }^{102}$
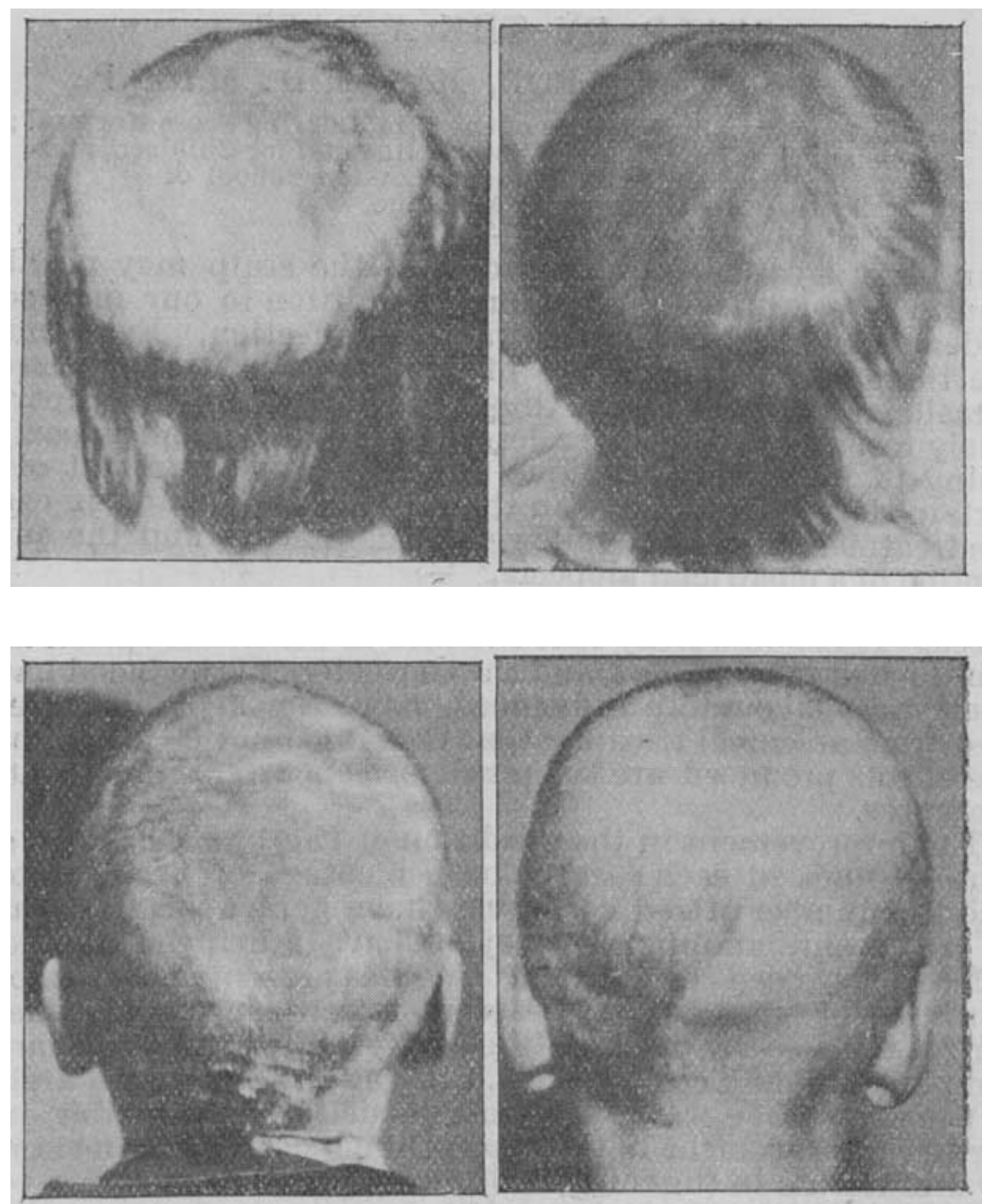

Figures 1.1 and 1.2 Photographs of X-ray depilation treatment of ringworm of the scalp. ${ }^{103}$ British Medical Journal, 1905, ii: 14. 
The number of published reports of success grew. These were typically of a small number of cases, with doctors cautioning that time was needed to assess whether the cures were permanent. John MacLeod, physician at Charing Cross Hospital and the Victoria Hospital for Children, did not regard X-rays as a panacea.

It is a treatment, however, which is by no means easy; first there are the difficulties of the technique, second there is the all-important local treatment with the parasiticide remedies, and, third, there is the care which is requisite to avoid mishaps.... The immediate dangers of the treatment...can, as a rule, be avoided, but with regard to the ultimate dangers, if there be any, sufficient time has not yet elapsed to disclose them. It has been suggested that the exposure of the scalp to the rays might have some harmful effect on the underlying brain. Certainly in an infant or a child under 3 years of age, where the scalp is thin and the fontanelles have not closed, one would be timid about submitting the scalp to the X-rays, but with regard to older children no misfortune of that nature has, as far as we are aware, been recorded. ${ }^{104}$

In fact, British dermatologists struggled to obtain results as good as those reported by Sabouraud; yet, even a 50\% cure rate was regarded as outstanding compared to other methods. ${ }^{105}$ Better results were anticipated once doctors developed mastery of the equipment and pastilles, and when patient compliance could be improved ${ }^{106}$ (see Figure 1.3).

The first systematic use of X-ray treatment in Britain was at the ringworm schools of the MAB; indeed, their success reportedly improved turnover so much that the Bridge School at Witham closed in 1908, saving $£ 500$ per year, when the remaining children were transferred to the Downs School. ${ }^{107}$ Treatment there was directed by Thomas Colcott Fox, with day-to-day matters in the hands of the school's medical officer Dr Sale. Within a year they reported 400 cures. ${ }^{108}$ The doctors enjoyed access to a large number of cases and developed facilities for treating many children at once (see Figure 1.4). They were treating pauper children, who were in triple isolation: in a special institution, within the Poor Law, and away from parents, hence, there were no problems with consent, and compliance with young children was largely a matter of discipline. Colcott Fox and Sale conducted a large 'trial', but as was typical for the time there were no controls. Unsurprisingly, when they published their results there was no discussion of the ethics of this 'trial', only wonder at its success. ${ }^{109}$ Indeed, the London County 


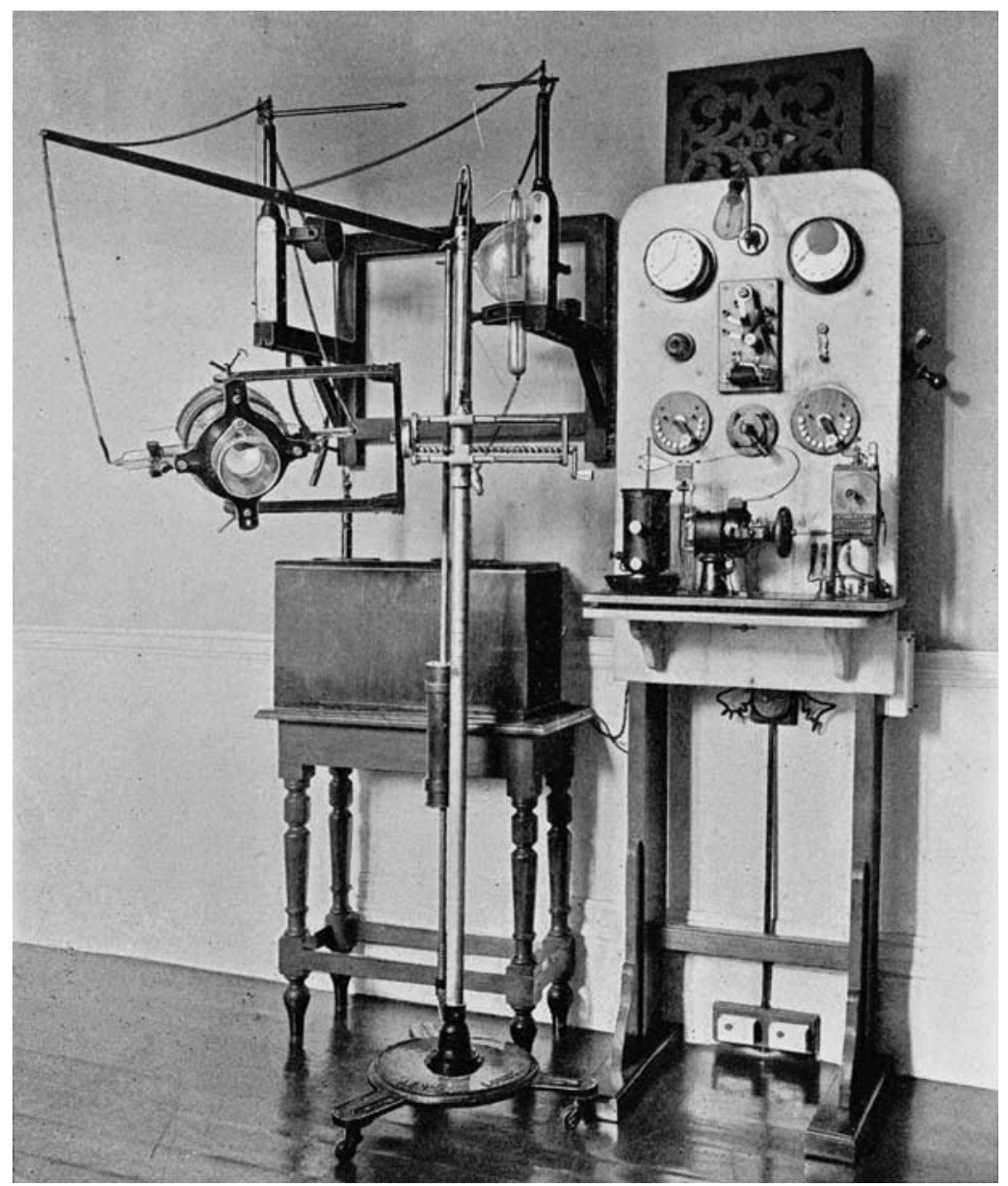

Figure 1.3 X-ray apparatus. Suitable for treatment of ringworm and other cutaneous affections. ${ }^{110}$ This figure (c) 2013 Wellcome Images is used under Creative Commons Attribution - Non-commercial licence: http:// creativecommons.org/licenses/by-nc/3.0/.

Council's Board of Education was so impressed that in 1907 it considered a scheme to provide free X-ray treatment for the capital's children at hospitals and special centres.

The Board's scheme was to be part of a larger plan of school medical inspection and treatment for pupils in elementary schools, that aimed to deal with a range of health problems: bad teeth, poor vision, 


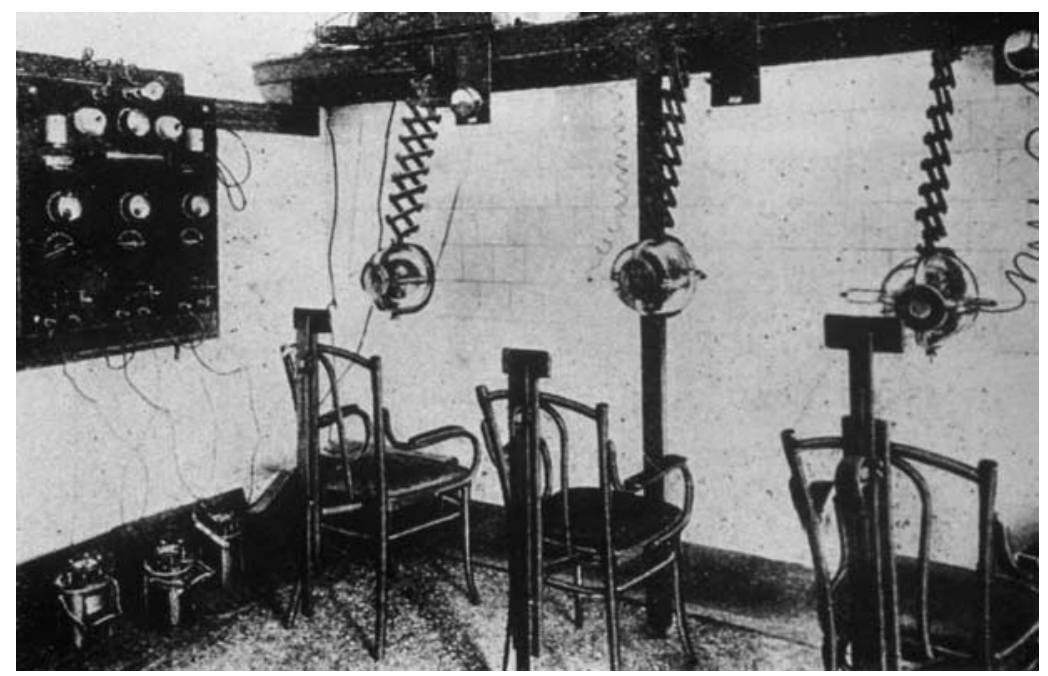

Figure 1.4 Radiotherapy room for ringworm. 1905. This figure is used courtesy of The Royal London Hospital Archives, Wellcome Images, 'This image is used under Creative Commons Attribution-NonCommercial-NoDerivs license: http://creativecommons.org/licenses/by-nc-nd/2.0/uk/

suppurating ears and adenoids, tuberculosis and general debility. ${ }^{111}$ These 'conditions' were seen as threats at three levels: to the long-term health and educational development of the child; to the efficient operation of schools; and to the progress of the race. Ringworm was taken up by the school medical service because they saw it being neglected by general practitioners, hospitals, public health authorities and parents. Proposals were considered in 1908 by a sub-Committee of the London County Council (LCC), which had replaced the MAB, which recommended that school clinics deal only with teeth defects, eye defects, skin diseases ('chiefly parasitic, such as, ringworm, scabies, pediculosis \& c.') and ear defects. ${ }^{112}$ In 1909 , this became policy and because of the anticipated high demand, ringworm treatment was contracted out to London voluntary hospitals, with children compelled to attend if ringworm was identified at school medical inspections. ${ }^{113}$ Other cities and large towns introduced similar schemes while outside of urban areas, where there were fewer or less well-resourced voluntary hospitals, older treatment regimes persisted. ${ }^{114}$

The official endorsement of X-ray treatment brought prompt criticism. Dr Dawson Turner, who worked in the Electrical Department at the 
Edinburgh Royal Infirmary and described himself as an 'old worker with X-rays', who had suffered permanent injury from exposures, wrote to the Times in March 1909, with what turned out to be a prescient caution.

The deleterious effects of continuous exposures to X-rays in the case of adults are only too well known to X-ray operators and it is probable that delicate cells of the growing brain of a child may be injuriously affected by much short exposures, though the evidence of impairment of function may not become noticeable until development is complete. No helpless child should have the chief centre of its nervous system exposed to the X-rays without the express consent of its parent, obtained after the possible risks of the treatment have been fully explained. ${ }^{115}$

His plea was answered in a report by two directors of London hospital electro-therapeutic departments. They stated that ordinary precautions had ensured no ill effects in their patients, nor did they expect any from other controlled uses of X-rays. ${ }^{116}$ However, the use of X-rays was resisted by some parents, though this was as much about distrust of hospitals and dislike of compulsion, as it was about worries over radiation. Mr Harris, a jeweller from Rotherhithe, on being instructed to take his daughter to Guy's Hospital, wrote back to the LCC's Child Care Branch stating he did not have 'much faith in those places' and that his wife, who was a trained nurse, was treating the child. ${ }^{117}$ Walter Longley asserted his independence in similar vein, saying that his boys were already being treated with sassafras oil and that his family would not trouble the LCC, nor the London ratepayer. ${ }^{118}$ Henry Carter wrote that the instruction to take his children to the Evelina Hospital was 'insulting to my wife and self'. ${ }^{119}$

Armed with X-rays and with the backing of the LCC administration, dermatologists and school medical offices were optimistic about the future control of ringworm. ${ }^{120}$ Nonetheless, in 1909, the Lancet set up an enquiry to address 'the grave prevalence' and 'the disastrous influence' ringworm was having on the education of children. ${ }^{121}$ The Lancet Commission on Ringworm, consisting of 'two thoroughly competent dermatologists' (who remained anonymous), reported on 1 January 1910. They dealt almost exclusively with the situation in London. ${ }^{122}$ The authors opened in eugenic terms, stating that ringworm was more prevalent in the 'less educated classes' and that those affected were 'really representatives of lower grades of civilisation', where infestation with 
internal and external parasites was a marker of being left behind by social progress. The authors endorsed X-ray treatment administered by dermatologists and radiotherapists, along with a positive assessment of the capacity of existing facilities to cope with the scheme of mass treatment that the LCC was contemplating. However, they were ambivalent about whether to use voluntary and local authority hospitals, or to recommend the creation of special treatment centres, but whatever was decided they were certain it would be cost-effective.

The Commission's report took seriously public concerns about the safety of X-rays, noting that in early years there had been accidents leading to permanent baldness and ulcers. However, burns were said to be a thing of the past as exposures were now well managed. With regard to brain damage, the authors wrote that the experience of thousands of cases, over many years, showed no evidence of any effects and that 'It is incumbent now on those who imagine that harm does follow the application of X-rays to produce the grounds for the view. ${ }^{123}$ Against this backdrop, many parents allowed their children to be treated with $\mathrm{X}$-rays but, as mentioned above, others refused. The manufacturers of popular alternatives, especially antiseptic creams like 'Germolene' and 'Zambuk' - 'The Balm that Benefits the Bairns', also offered their products as direct alternatives to X-rays. ${ }^{124}$ However, some medical officers raised the stakes. For example, Dr Bostock Hill, the Medical Officer of Health for Warwickshire, claimed in 1911 that he instructed parents that 'they would be dealt with under the Children's Act for cruelty ... or the case would be referred to the N.S.P.C.C' [National Society for the Protection of Children], if they refused to allow their children to be treated. ${ }^{125}$

Ernest Dore, a dermatologist at the Evelina Hospital for Sick Children, made a telling observation in his review of X-ray treatment in 1911, a year after the publication of the Lancet Commission report. ${ }^{126}$ He returned to the issue of stigma, arguing that before X-ray treatments a diagnosis of ringworm was far worse than any physical suffering.

A trivial complaint as regards the health of the child, tinea tonsurans brings in its train so long a category of ills that I have more than once heard long-suffering mothers say that they dreaded scarlet fever or pneumonia less. The disorganisation of the home that ensues from the isolation of the sufferers; the anxiety of the parents lest other children in the family should become infected; the complications with medical men and schoolmasters; the social ostracism; the loss of schooling; the wearisome process of constantly rubbing on 
ointments with little apparent result except the production of sore heads in the children and sore hearts in the parents, these are some of the difficulties which have to be faced under the old régime. ${ }^{127}$

Given the reactions of children, family, friends, neighbours, teachers and doctors to ringworm, and its position as a marker of 'low civilisation' and social danger, it is clear why a disease that never killed or caused permanent injury attracted such high-profile medical and public attention. Indeed, Dore wanted to up the stakes further, hinting at the possibility of stamping out the disease if compulsion was used: either in prevention, 'such as the wearing of some kind of head gear, like the muzzle in the prophylaxis of rabies', or with X-ray treatment.

A national picture of ringworm in school children was represented in the Reports of the Medical Officer to the Board of Education, Dr George Newman; the first of which was for $1908 .{ }^{128}$ The prevalence of ringworm was around $1 \%$ amongst children inspected in school, much lower than other 'defects', which were: vision (10\%), hearing (3-5\%), adenoids and enlarged tonsils (6-8\%), tooth decay (40\%) and unclean bodies or heads (30-40\%). ${ }^{129}$ The main issue with ringworm was exclusion and its effects on a child's education; plus, from an administrative perspective, the impact of long absences on a school's grant income. Although prevalence was low, it still meant that, on average, 3,000 children were absent every day, with a typical absence duration of nine weeks. ${ }^{130}$ Nationally, the longest average exclusion reported of 29 weeks was in Somerset. This finding was seen as surprising for a rural county with few large towns and low population density, and was attributed to poor inspection regimes causing early cases to be missed. Although impetigo, by this time associated with Staphylococcus aureus infection, was the most prevalent skin disease found in inspections, ringworm was taken much more seriously. ${ }^{131}$ Dr Ritchie, the School Medical Officer for Manchester, reported that inspections in 1913 had revealed the following: impetigo - 353, ringworm - 187, scabies - 39 and other skin diseases $-110 .{ }^{132}$ However, cases reported by doctors and parents led to 2,003 notifications of ringworm in the city, with up to 1,500 children under supervision at any time. The Manchester containment regime was strict, ' . . no cases of ringworm of the scalp are allowed to attend school unless the hair over and around the patches is cut and a washable cap worn.... Children affected with ringworm of the body are not allowed to attend school. ${ }^{133}$ In the same year, a ringworm school was established in Edinburgh for long-term absentees, including one boy who allegedly had been excluded for four years. ${ }^{134}$ 
In his annual reports, Newman began to report improvements, particularly in areas where X-ray treatment was available. In London, new cases fell from 5,573 in 1913 to 4,449 a year later, while in Beckenham in Kent, new cases had fallen from 133 in 1911 to just 48 in $1914 .{ }^{135}$ However, nationally, the provision of special services was patchy. Only one third of education authorities had made special provision for ringworm treatment and in many areas, especially outside of cities and large towns, there was still no access to X-ray treatment at all. In addition, many general practitioners chose to continue to recommend topical fungicides and left treatment to 'unreliable' parents. ${ }^{136}$

\section{The decline of ringworm}

In Britain, doctors reported that the incidence of ringworm of the scalp in school children fell during the First World War, but increased afterwards because of the shortage of school nurses, many of whom continued to work with casualties and invalids. ${ }^{137}$ However, this was a minor peak as the incidence fell steadily over the inter-war period. In London, the number of new cases had reduced from 6,214 in 1911, to 3,983 in 1920. The number dropped further, to 513 in 1930 and by 1936 they was just $89 .{ }^{138}$ As early as 1925 , the district medical officer for Beckenham reported no new cases, while in Ilford, ringworm was also said to have been 'abolished'. ${ }^{139}$ In his 26th and final report, for the year 1933, George Newman observed with satisfaction that 'Ringworm is steadily disappearing. ${ }^{140}$ This situation was reflected in treatment facilities, the number of which was reduced from 150 clinics in 1923 to 80 in 1938. The London ringworm school, which had moved to the Goldie Leigh Cottage Children's Homes, Woolwich, in 1914, took fewer and fewer residential cases, and became instead a centre for day treatment with X-rays. ${ }^{141}$

Doctors attributed the decline in the reported incidence of ringworm, in the words of Norman Walker in 1929, not so much to the character of the infection, but to 'the value of cooperation between the scientist, the clinician, and the organiser' ${ }^{142}$ Success was said to have come from school inspection spotting early cases, which were followed up by effective treatments such as X-rays. The provision and use of X-rays was variable across the country. In the early 1930s only $20 \%$ of diagnosed cases in England were receiving X-rays. The rates of use varied: London was the highest and rural counties were several times lower ${ }^{143}$ (Table 1.1). 
Table 1.1 Cases of ringworm in England and Wales treated by X-ray or other methods, 1933

\begin{tabular}{lrrr}
\hline England & By X-rays & Otherwise & $\begin{array}{c}\text { X-ray treatment as } \\
\text { percentage of total }\end{array}$ \\
\hline Counties & 149 & 2058 & 6.8 \\
County boroughs & 540 & 2040 & 20.9 \\
Boroughs & 120 & 597 & 16.7 \\
Urban districts & 22 & 90 & 19.6 \\
London & 160 & 18 & 89.9 \\
Wales & & & \\
Counties & 20 & 88 & 18.5 \\
County boroughs & 52 & 19 & 73.2 \\
Boroughs & 0 & 24 & 0.0 \\
Urban districts & 7 & 29 & 19.4 \\
\hline
\end{tabular}

Chemical and mechanical methods of depilation continued to be used and there was particular interest again in the 1930s in giving thallium acetate. ${ }^{144}$ Some doctors, particularly in the United States, argued that thallium treatment was safer than X-rays; however, critics termed it 'A Dangerous Drug' because the margin between achieving effective epilation and poisoning was very small. ${ }^{145}$ During the inter-war period, dermatologists on both sides of the Atlantic showed less interest in ringworm of the scalp, reflecting lower incidence and relatively stable therapeutic regimes. ${ }^{146}$ Their new areas of interest were ringworm in athletes, college students, soldiers and miners.

Ringworm, although no doubt a common human infection for centuries, only gained serious medical and public attention in the second half of the nineteenth century, and then in a specific social group and setting: school children and schooling. The aggregation of children in crowded classrooms for hours at a time seemed to provide ideal conditions for contagion. None the less, it was as a social rather than physical disease that ringworm gained medical and public attention. Ringworm epidemics were one of the unintended consequences of the progressive reform of mass schooling, which revealed changing social attitudes to markers of disease and the growing stigmatisation of the palpably 'unclean'. While historians such as Nancy Tomes have detailed public responses to the threat of invisible germs, we have revealed the reactions, some similar and others unique, to conditions where the germs were highly visible. Perhaps, the 'gospel of germs' won converts more readily for diseases such as ringworm, favus and trachoma, where 
the physical and social manifestations of infection were obvious and reinforcing.

From 1905, ringworm was also seen as a pathology that could be remedied by medical progress, and not just any new technology, but by the medical icon of the age, X-rays. The use of X-ray depilation was an innovation that was taken up rapidly, in large measure because it promised so much, but also because the necessary equipment was becoming more readily available and there were opportunities for clinical and organisational innovations. In Britain, major public bodies such as the LCC, having been persuaded to create special ringworm institutions, subsequently invested in the new technologies of treatment. This all seemed to pay off, as the reported incidence of ringworm of the scalp in children declined rapidly in the inter-war period. ${ }^{147}$ There was debate about the causes of the fall. Was it due to medical inspection regimes and new treatments, or to social factors, such as more bathrooms, better medicated shampoos, the fashion for shorter hair and grooming with hair creams? 'Brylcreem' was introduced in 1928 and marketed for better 'bounce' in styling and control of dandruff, then said to be caused by a yeast fungus Pityrosporon. Whatever the specific reasons, all factors responsible for the decline were seen by contemporary commentators to be due to medical and social progress.

Except where otherwise noted, this work is licensed under a Creative Commons Attribution 3.0 Unported License. To view a copy of this license, visit http://creativecommons.org/licenses/by/3.0/ 